\title{
Идентификация сортов яровой пшеницы (Triticum aestivum L.) Ce- верного Зауралья на основе полиморфизма глиадинов
}

Утебаев М.У.', аспирант; Боме Н.А. ${ }^{l}$, д.с.-х.н., проф. зав. кафедрой ботаники, биотехнологии и ландшафтной архитектуры; Чилимова И.В. ${ }^{2}$, м.н.с.; Крадеикая O.O. ${ }^{2}$, м.н.с.

${ }^{\prime}$ ФГАОУ ВО «Тюменский государственныий университет», Тюмень, Россия; ${ }^{2}$ ТОО «Научно-производственный иентр зернового хозяйства им. А.И. Бараева», Шортанды, Казахстан.

*e-mail: ${ }^{1}$ phytochem@yandex.ru; ${ }^{2}$ tsenter-zerna@mail.ru

По результатам электрофореза глиадина коллекиии из 29 сортов пшеницы тюменской селекции, проведена идентификация аллельного разнообразия глиадинкодирующих локусов. Наиболее часто встречались аллели Gli-Alf (51,2\%), Gli-Ble (48,7\%), Gli-Dla (51,2\%), Gli-A2m (29,3\%), GliB2o $(21.9 \%)$ и Gli-D2q (31,7\%). Комбинация данных аллелей в генотипе могут быть ценными для селекиии высококачественных сортов яровой мягкой пшеницы, адаптированных к условиям Северного Зауралья.

Ключевые слова: Gli-локусы, пшеница, селекияи, генотип, глиадин.

\section{Identification varieties of common wheat (Triticum aestivum L.) from Northern Trans-Urals on gliadin polymorphism}

${ }^{1}$ Utebayev M.U., post-graduate student, ${ }^{1}$ Bome N.A.., DSc of Agriculture, Prof. Head of Department of Botany, Plant Biotechnology and Landscape Architecture. ${ }^{2}$ Chilimova I.V., Junior Researcher, ${ }^{2}$ Kradetskaya O.O. Junior Researcher ${ }^{1}$ University of Tyumen, Tyumen, Russia,phytochem@yandex.ru

2 A.I. Barayev Research and Production Centre of Grain Farming, Shortandy-1, Kazakhstan.

According to the results of gliadin electrophoresis of a collection of $29 \mathrm{va}$ rieties of wheat from Tyumen selection, was identified the allelic diversity of gliadin coding loci. The most common alleles are Gli-Alf (51.2\%), Gli-Ble (48.7\%), Gli-D1a (51.2\%), Gli-A2m (29.3\%), Gli-B2o (21.9\%) and Gli-D2q (31.7\%). The combination of these alleles in the genotype can be valuable for the breeding of high-quality varieties of common wheat adapted to the conditions of the Northern Trans-Urals region.

Keywords: breeding, Gli-loci, genotype, gliadin, wheat.

Глиадин является сортоспецифичным, генетически детерминированным белком, не зависящим от условий и места произрастания. Генетический 
контроль синтеза данного белка осуществляется шестью основными кластерами генов локализованных в коротких плечах хромосом первой и шестой гомеологичных групп [1]. При электрофоретическом разделении глиадин дает богатый спектр белковых компонентов и может применяться для выявления генетической изменчивости растения. Поэтому, использование проламинов в качестве белковых маркеров при идентификации растительного материала, контроле их генетической структуры, установления их однородности, стабильности и отличимости (подлинности) не потеряло своей актуальности и на сегодняшний день.

Целью исследования являлась идентификация генотипов сортов яровой мягкой пшеницы тюменской селекции, с помощью аллельных вариантов глиадинкодирующих локусов.

Материал и методы исследования. Объектом исследования служили 29 сортов яровой мягкой пшеницы тюменской селекции. Электрофорез и идентификацию аллелей проводили на основе методик опубликованных ранее $[2,3]$. В качестве стандарта при электрофорезе использовался сорт Безостая 1.

Результаты и обсуждение. По каждому локусу идентифицировано различное количество аллелей, так например, по локусам $A 1$ и $D 1$ обнаружено 9 аллелей, локус В1 представлен 6 аллелями. По локусам Gli-2 идентифицировано 13 аллелей для локуса $A 2,14$ по локусу $B 2$ и 11 аллелей по локусу $D 2$ (рисунок).

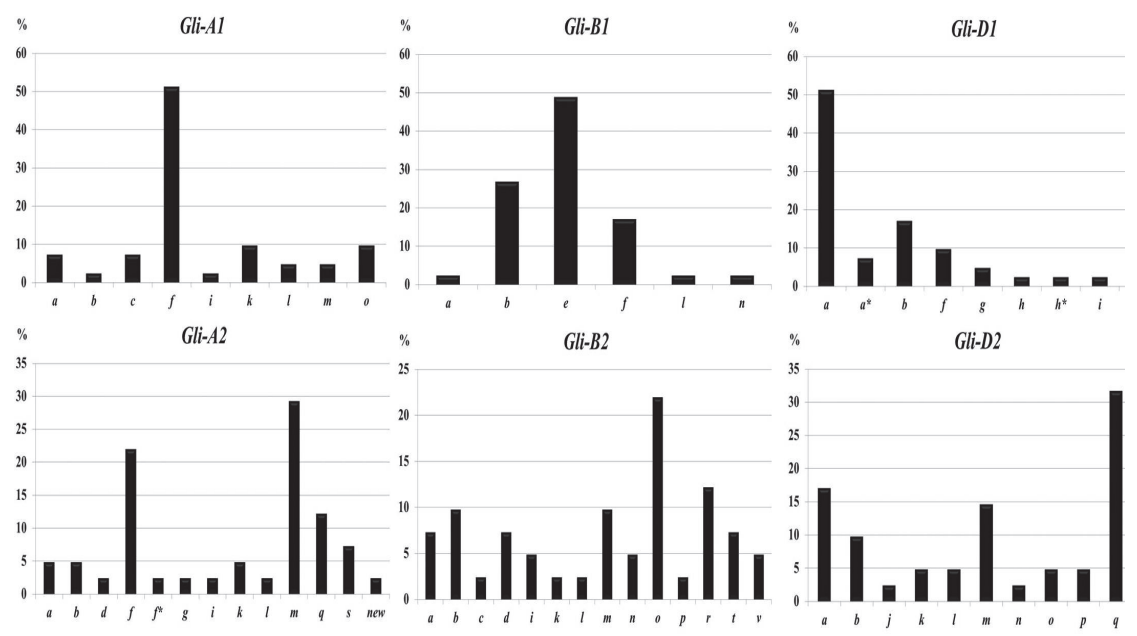

Рисунок. Частоты встречаемости (\%) аллелей глиадинкодирующих локусов яровой мягкой пшеницы 
Анализ генетических формул глиадина показал, что по локусам 1 гомеологичной группы - Gli-1, преимущественно встречались аллели: Gli-Alf с частотой 0,51 ; Gli-Ble $-0,49 ;$ Gli-Dla $-0,51$. По локусам 6 гомеологичной группы Gli-2, такие аллели как: Gli-A2m-0,29; Gli-B2o-0,22 и Gli-D2q0,32 .

При сравнительном анализе аллельного состава, оказалось, что аллели Gli-Alf, Gli-Ble, Gli-Dla являются общими для мягкой пшеницы омской, саратовской [4] и северо-казахстанской [5] селекции. Было выдвинуто предположение, что локусы Gli, расположенные на хромосомах 6 гомеологичной группы, сопряжены с адаптивными признаками растений, тогда как локусы хромосом 1 гомеологичной группы контролируют хлебопекарное качество [4]. Ранее, также было установлено, что хлебопекарная изменчивость связана большей частью с аллельным разнообразием локусов Gli-1 [6].

Заключение. По результатам электрофореза глиадина коллекции из 29 сортов пшеницы тюменской селекции, проведена идентификация аллельного разнообразия глиадинкодирующих локусов, составлены генетические формулы. На основе полученных результатов определены аллели с наибольшей частотой, встречающиеся в коллекционном материале. Так, наиболее часто встречаются аллели Gli-Alf (51,2 \%), Gli-Ble (48,7\%), Gli-Dla (51,2 $\%)$, Gli-A2m (29,3\%), Gli-B2o (21.9\%) и Gli-D2q (31,7\%), комбинация которых в генотипе могут быть ценными для селекции высококачественных сортов яровой мягкой пшеницы, адаптированных к условиям Северного Зауралья.

\section{Список литературь}

1. Metakovsky E.V. Recombination mapping of some chromosome 1A-, 1B-, 1D- and 6B-controlled gliadins and low-molecular-weight glutenin subunits in common wheat / E.V. Metakovsky, G.P. Branlard, V.M. Chernakov, V.P. Upelniek, R. Redaelli, N.E. Pogna // Theor Appl Genet. - 1997. - V. 94. - P. 788-795.

2. Metakovsky E.V. Gliadin allele identification in common wheat. 1. Methodological aspects of the analysis of gliadin pattern by one-dimensional polyacrylamide - gel electrophoresis / E.V. Metakovsky, A.Yu. Novoselskaya // J. Genet Breed. - 1991. - 45. - P. $317-$ 324.

3. Metakovsky E.V. Gliadin allele identification in common wheat. 2. Cataloque of gliadin alleles in common wheat // J. Genet. Breed. - 1991. - V. 45. - P. 325-344.

4. Novoselskaya-Dragovich A.Yu. Genetic differentiation of common wheat cultivars using multiple alleles of gliadin coding loci / A.Yu. Novoselskaya-Dragovich, A.V. Fisenko, V.A. Puhal'skii // Russian J. of Genetics. - 2013. - V. 49. - N. 5. - P. 487-496.

5. Utebayev M. Genetic diversity of gliadin-coding alleles in bread wheat (Triticum aestivum L.) from Northern Kazakhstan / M. Utebayev, S. Dashkevich, N. Bome, K. Bulatova, Y. Shavrukov // PeerJ. - 2019. - 7. - e7082.

6. Li Y. Detection of QTLs for breadmaking quality in wheat using a recombinant inbred line population / Y. Li, Y. Song, R. Zhou, G. Branlard, J. Jia // Plant Breeding. - 2009. - № 128 . - P. 235-243. 